\title{
Intraventricular catheter placement by electromagnetic navigation safely applied in a paediatric major head injury patient
}

\author{
Christoph Alexander Aufdenblatten - Stefan Altermatt
}

Received: 6 May 2008 / Published online: 17 June 2008

(C) Springer-Verlag 2008

Keywords Intracranial pressure · Children .

Neuronavigation · Traumatic brain injury · Monitoring ·

Lateral ventricle $\cdot$ Intraventricular pressure

\begin{abstract}
Introduction In the management of severe head injuries, the use of intraventricular catheters for intracranial pressure (ICP) monitoring and the option of cerebrospinal fluid drainage is gold standard. In children and adolescents, the insertion of a cannula in a compressed ventricle in case of elevated intracranial pressure is difficult; therefore, a pressure sensor is placed more often intraparenchymal as an alternative option.

Discussion In cases of persistent elevated ICP despite maximal brain pressure management, the use of an intraventricular monitoring device with the possibility of cerebrospinal fluid drainage is favourable. We present the method of intracranial catheter placement by means of an electromagnetic navigation technique.
\end{abstract}

\section{Introduction}

Elevated intracranial pressure (ICP) after head trauma is usually managed conservatively. ICP monitoring is a corner stone in the management of severely injured patients (Glasgow Coma Scale, GCS $\leq 8$ ) because of the high risk for intracranial hypertension $[1,12,15]$. Gold standard is the placement of a pressure sensor intraventricular catheter as the most accurate and reliable method for ICP monitoring [1, 3, 4, 14, 19]. It also allows therapeutic cerebrospinal fluid (CSF) drainage. However, in our experience, the placement of an intraventricular catheter in traumatic brain injury in children is difficult because these patients often have very small ventricles. For this reason, an ICP sensor is placed in the brain parenchyma in most cases as an alternative option, lacking the possibility of CSF drainage.

We present the case of a paediatric traumatic brain injury patient with small ventricles and persistent elevated ICP levels despite maximal conservative management and in whom we placed an intraventricular catheter (Neuro Monitor Catheter $\mathrm{Kit}^{\mathrm{TM}}$, Codman ${ }^{\circledR}$, Berkshire, UK) by using AxiEM $^{\mathrm{TM}}$ electromagnetic navigation (StealthStation ${ }^{\circledR}$, Medtronic Surgical Navigation Technologies, Louisville, CO, USA).

\section{Case report H.M., 30.8.92}

Department of Pediatric Surgery,

University Children's Hospital Zurich,

Steinwiesstrasse 75 ,

8032 Zurich, Switzerland

C. A. Aufdenblatten $(\bowtie)$

Department of Pediatric Surgery, Children's Hospital, 6000 Lucerne, Switzerland

e-mail: christoph.aufdenblatten@ksl.ch
A 14-year-old boy sustained a major head injury by skiing. The boy was wearing a helmet. The initial GCS reported by the helicopter rescue team was 6 before intubation at the place of accident. On arrival at our emergency department, the patient was sedated, ventilated and cardiopulmonary 


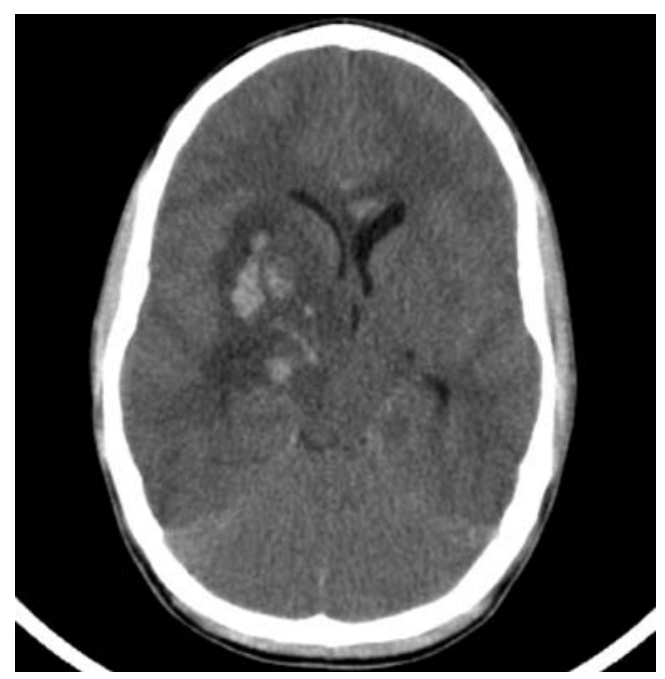

Fig. 1 Follow-up CT, parenchymal injuries, diffuse brain oedema and haemorrhage into the lateral ventricles

stable. The limited neurologic examination revealed a GCS of 3 with both pupils moderately dilated and with absent reaction to light. There was a small haematoma on the right forehead. Computed tomography (CT) scan revealed massive intracerebral shearing injuries in the parenchyma and in the basal ganglia of the right hemisphere as well as a haemorrhage into the right lateral ventricle. There was also a declined volume of the inner and outer CSF compartments, suggesting increased ICP. An ICP monitoring was set up by inserting a pressure sensor (Microsensor, Codman ${ }^{\circledR}$ ) into the brain parenchyma of the left hemisphere. The first ICP measured was $14 \mathrm{mmHg}$, whereas cerebral perfusion pressure (CPP) was $80 \mathrm{mmHg}$. Followup CT scan after $24 \mathrm{~h}$ showed diffuse brain oedema and progressive signs of increased ICP as well as blood in the lateral ventricles (Fig. 1). Despite a maximal CPP-based ICP management (analgesia, sedation, muscle relaxation, cardiopulmonary support and hypertonic electrolyte substitution), recurrent ICP peaks of $>20 \mathrm{mmHg}$ occurred during the following days. To optimize the ICP management by draining CSF, we inserted on day 3 after admission a Codman ${ }^{\circledR}$ ICP microsensor intraventricular catheter into the left lateral ventricle through a left pre-coronal borehole. Because of small ventricles surrounded with parenchymal lesions, we decided to insert the intraventricular catheter navigated by the StealthStation ${ }^{\circledR}$ Treon ${ }^{\circledR}$ with AxiEM ${ }^{\mathrm{TM}}$ electromagnetic navigation (Medtronic Surgical Navigation Technologies, Louisville, CO, USA). The operation was successful (Fig. 2).

After this intervention, the ICP peaks $>20 \mathrm{mmHg}$ were managed by intermittent drainage of CSF through the intraventricular catheter. By this management, ICP was maintained constantly $<20 \mathrm{mmHg}$ over the next few days, and the ICP pressure therapy was reduced step by step. On day 12 after admission, the ICP monitoring catheter was removed, and the patient woke up. The neurologic evaluation after extubation revealed a left-sided hemiparesis and aphasia, corresponding to the initial brain injury shown in the first CT scan. On day 18 after admission, the patient was transferred to our rehabilitation facility.

\section{Technical approach}

To plan the electromagnetic-navigation-guided intraventricular catheter placement, one needs an actual CT or magnetic resonance imaging investigation of the patient to load to the StealthStation ${ }^{\circledR}$ Treon ${ }^{\circledR}$ before the operation (Fig. 3). In the operating room, the patient is positioned supine on the operating table. For the AxiEM ${ }^{\mathrm{TM}}$ Technology, a patient tracker is placed on the patient's skull as a dynamic reference frame through a small skin incision. The AxiEM ${ }^{\mathrm{TM}}$ Localizer generating an electromagnetic field is positioned right beside the patient's head under the sterile cover sheet (Fig. 4). After a small skin incision and a borehole trepanation, the intraventricular catheter (Codman ${ }^{\circledR}$ Neuro Monitor Catheter) is introduced over an ultra-thin stylet incorporating single-coil navigation technology providing tip tracking on the monitor of the StealthStation ${ }^{\circledR}$ Treon ${ }^{\circledR}$ standing in front of the surgeon (Fig. 4).

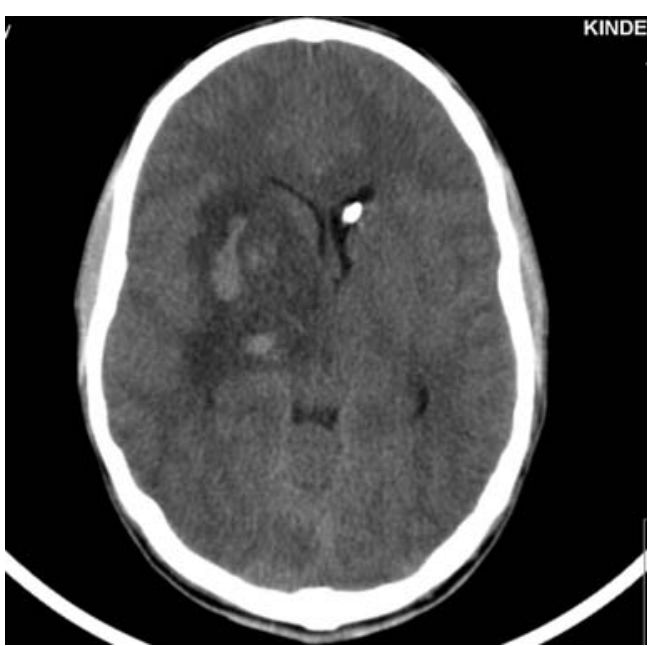

Fig. 2 CT after placement of intraventricular catheter 
Fig. 3 CT loaded in

StealthStation ${ }^{\circledR}$ Treon ${ }^{\circledR}$; operations planning performed
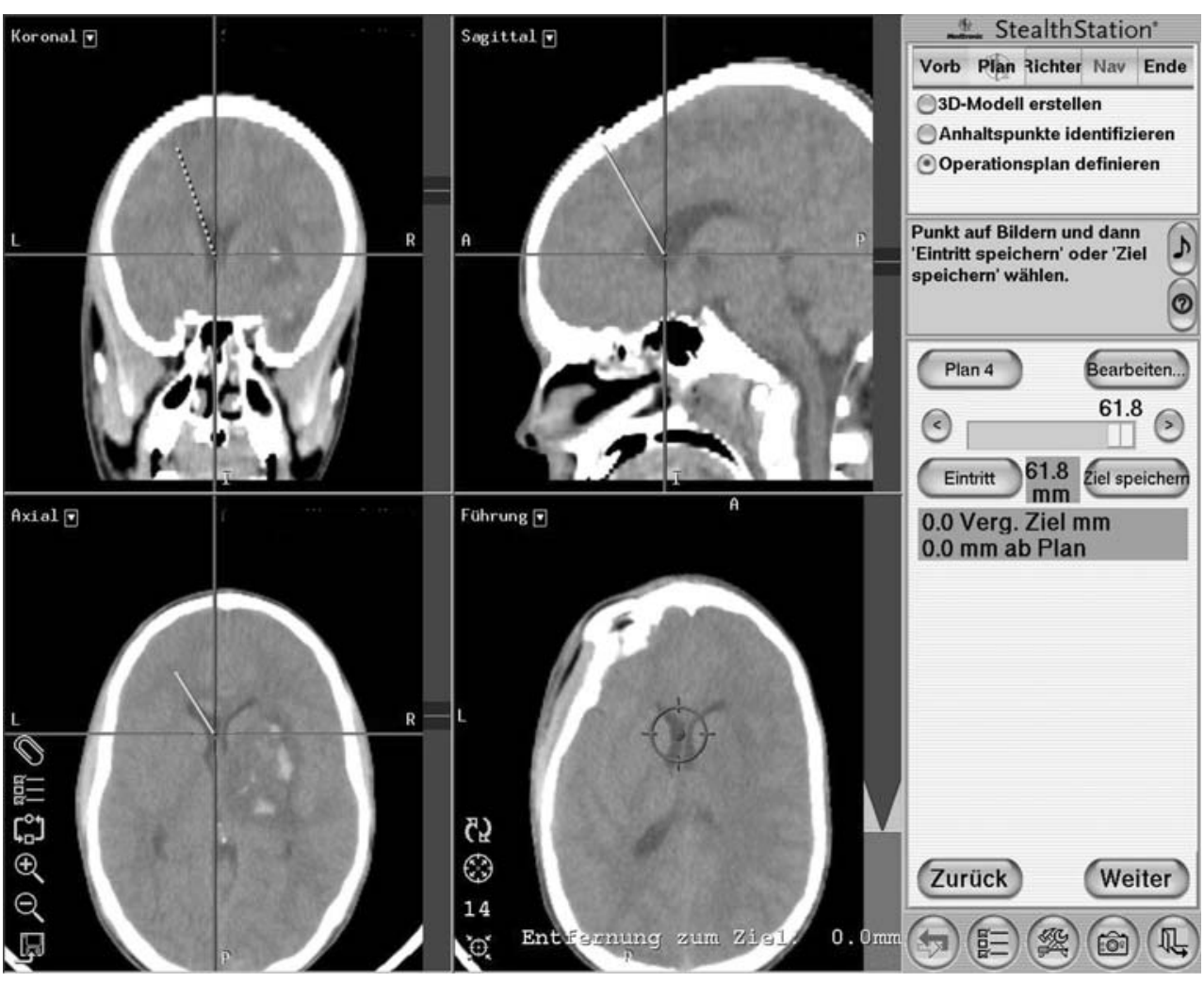

\section{Discussion}

Literature on methods of measuring ICP in children is relatively rare, and there is no clear guidance on where to measure ICP in routine clinical practice [19]. In the 1960s, Lundberg et al. developed intraventricular pressure moni- toring $[9-11,14,19]$. Ventricular catheterization remains the criterion standard for ICP measurement today $[1,3,4$, $7,18,19]$. Nevertheless, intraventricular catheters are rarely placed because of technical difficulties with cannulating a compressed or deviated ventricle in situations with elevated ICP and a higher complication rate. Morris et al. reported a
Fig. 4 AxiEM $^{\mathrm{TM}}$ electromagnetic tracking device and StealthStation ${ }^{\circledR}$ Treon ${ }^{\circledR}$ in front of the surgeon

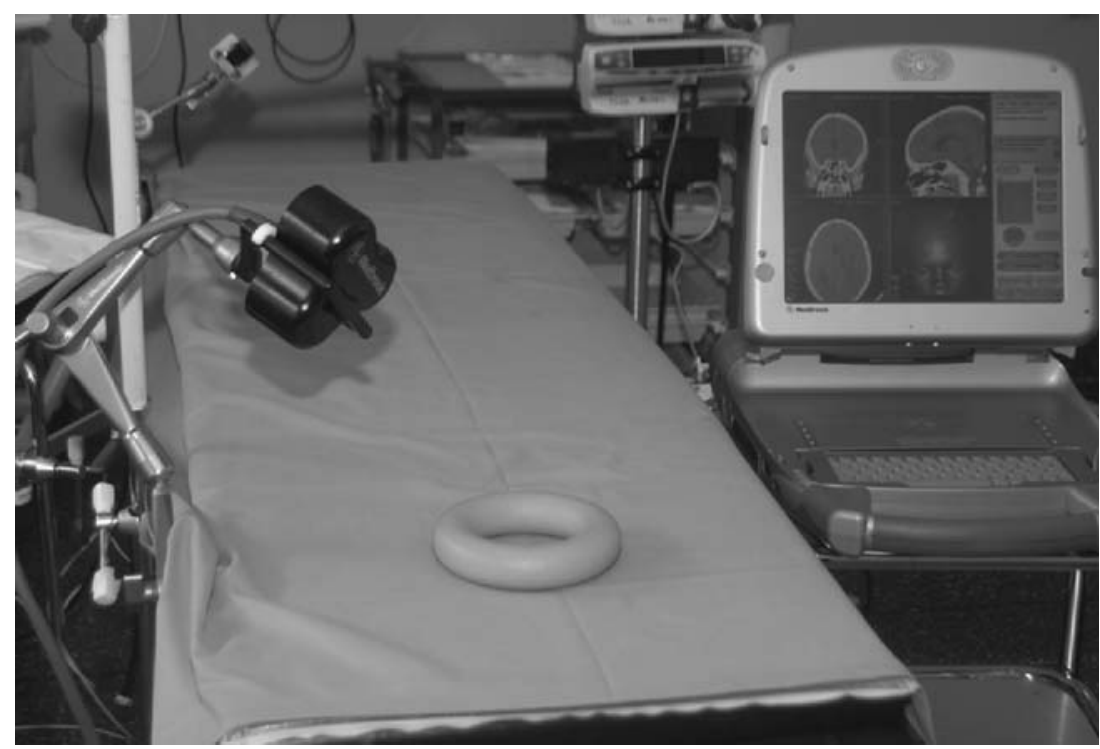


rate of intraventricular catheter usage of only $6 \%$ in 501 children treated for severe traumatic brain injury in the UK and Ireland during a 1-year study period [14]. Furthermore, risks of haemorrhagic complications with intraventricular cannulation are higher (up to $15 \%$ ) than with intraparenchymal devices $[13,17,19]$. Infection rate varies between $1 \%$ and $2 \%$ with intraparenchymal devices but is found in up to $5 \%$ of intraventricular devices $[2,16,19]$. Currently, the intraparenchymal ICP monitoring devices have proven to be the most reliable ones in daily practice because they are easy to place, have very few infectious complications and are simple to handle $[5,8,19]$. In our opinion, the intraventricular catheters for monitoring ICP should be used as an alternative option to the intraparenchymal ones in cases of persistent elevated ICP levels despite maximal conservative management, with the need of CSF drainage for effective brain pressure management. In our case, we inserted the catheter with electromagnetic navigation. This neuronavigation technique is designed for use across several surgical specialities including neurosurgery, spinal surgery, orthopedics, as well as ear, nose and throat surgeries worldwide, and provides a safe and easy way to insert intraventricular catheters in paediatric traumatic brain injury patients. Neuronavigated ventricular catheter placement is reported as a safe procedure for hydrocephalus children with small ventricles or abnormal ventricular anatomy [6]. As to our knowledge, the use of this technique in paediatric trauma patients has not been reported yet.

\section{References}

1. Adelson PD, Bratton SL, Carney NA, Chesnut RM, du Coudray HE, Goldstein B, Kochanek PM, Miller HD, Partington MD, Selden NR, Warden CR, Wright DW (2003) Guidelines for the acute medical management of severe traumatic brain injury in infants, children, and adolescents. Pediatr Crit Care Med 4(3 Suppl): S1-S75

2. Anderson RCE, Kan P, Klimo P, Brockmeyer DL, Walker ML, Kestle JRW (2004) Complications of intracranial pressure monitoring in children with head trauma. J Neurosurg 101(Suppl. 1): 53-58

3. Brown E (1988) Intracranial pressure monitoring devices. Association for the Advancement of Medical Instrumentation, Arlington, VA
4. Bullock R, Chesnut RM, Clifton G, Ghajar J, Marion DW, Narayan RK, Newell DW, Pitts LH, Rosner MJ, Wilberger JW (2000) Guidelines for the management of severe traumatic brain injury. J Neurotrauma 17:451-553

5. Gelabert-Gonzalez M, Ginesta-Galan V, Sernamito-Garcia R, Allut AG, Bandin-Diéguez J, Rumbo RM (2006) The Camino intracranial pressure device in clinical practice. Assessment in 1000 cases. Acta Neurochir 148:435-441

6. Gil Z, Siomin V, Beni-Adani L, Ben Sira L, Constantini S (2002) Ventricular catheter placement in children with hydrocephalus and small ventricles: the use of a frameless neuronavigation system. Child's Nerv Syst 18:26-29

7. Kiefer M, Steudel WI (2002) Modern intracranial pressure measurement techniques. Basic principles and general practice. Unfallchirurg 105:578-586

8. Luerssen TG (1997) Intracranial pressure: current status in monitoring and management. Semin Pediatr Neurol 4:146-155

9. Lundberg N (1960) Continuous recording and control of ventricular fluid pressure in neurosurgical practice. Acta Psychiatr Scand 36:1-193

10. Lundberg N, West KA (1965) Leakage as a source of error in measurement of the cerebrospinal fluid pressure by lumbar puncture. Acta Neurol Scand 1(Suppl 13):115-121

11. Lundberg N, Troupp H, Lorin H (1965) Continuous recording of the ventricular-fluid pressure in patients with severe acute traumatic brain injury. A preliminary report. J Neurosurg 22:581-590

12. Marmarou A, Anderson RL, Ward JD (1991) Impact of ICP instability and hypotension on outcome in patients with severe head trauma. J Neurosurg 75:S59-S66

13. Miller T, Pasquale M, Kurek S, White J, Martin P, Bannon K, Wasser T, Li M (2004) Initial head computed tomographic scan characteristics have a linear relationship with initial intracranial pressure after trauma. J Trauma 56:967-973

14. Morris KP, Forsyth RJ, Parslow RC, Tasker RC, Hawley CA (2006) Intracranial pressure complicating severe traumatic brain injury in children: monitoring and management. Intensive Care Med 32:1606-1612

15. Narayan RK, Greenberg RP, Miller JD (1981) Improved confidence of outcome prediction in severe head injury: a comparative analysis of the clinical examination, multimodality evoked potentials, CT scanning and intracranial pressure. J Neurosurg 54:751-762

16. Pople IK, Muhlbauer MS, Sanford RA, Kirk E (1995) Results and complications of intracranial pressure monitoring in 303 children. Pediatr Neurosurg 23:64-67

17. Rossi S, Buzzi F, Paparella A, Mainini P, Stocchetti N (1998) Complications and safety associated with ICP monitoring: a study of 542 patients. Acta Neurochir 71:91-93

18. Tilford JM, Simpson PM, Yeh TS, Lensing S, Aitken ME, Green JW, Harr J, Fiser DH (2001) Variation in therapy and outcome for pediatric head trauma patients. Crit Care Med 29:1056-1061

19. Wiegand C, Richards P (2007) Measurement of intracranial pressure in children: a critical review of current methods. Dev Med Child Neurol 49:935-941 